SHS Web of Conferences 19, 01006 (2015)

DOI: $10.1051 /$ shsconf/ 20151901006

(C) Owned by the authors, published by EDP Sciences, 2015

\title{
Analyses on How to Permeate Psychological Health Education in College English Teaching
}

\author{
Yifei Wang \\ Department of Foreign language, Jiujiang University, 332005 Jiujiang Jiangxi, China
}

\begin{abstract}
College students' mental health education research has become an important subject of psychological research in our country. Questionnaire survey and analysis are conducted on the adaptability to the campus life of college students. And we may have better and more effective college English teaching methods through this research. The data used in this paper come from 100 freshmen from Jiujiang University, majoring in Business English. Based on the analysis of the data, the following findings are obtained. By analyzing the psychological problems in college students' learning process and putting forward the method to solve those problems, universities should carefully summarize the good experience and characteristics, and explore new ideas actively on college students' psychological health education work to encourage students to learn English better.
\end{abstract}

Keyword. college students; mental health; English teaching

\section{Introduction}

China started late on college students' mental health education, which experienced a process from knowing it to valuing it then to strengthening it. Talents in the 21 st century should have good moral quality and broad scientific and cultural quality. Universities should develop students' good physical and mental qualities and encourage them to remain being optimistic and positive. We have ignored the students' psychological quality education for a long time, so there are a lot of college students' psychological problems. Nowadays, most college students are from single-child family and they have superior living conditions. Pampered by their parents, some youngsters are selfish, vulnerable and fear to suffer. Many students with weak wills are always frustrated when facing difficulties. College students' mental health problems such as suicide, crime, school dropouts and mental disorders all occur frequently. Therefore, our modern society urgently calls for college students with healthy psychology.

Language skill is one of most important basic skills for contemporary college students, and it has been one of the compulsory subjects in university, so it has great significance on how to penetrate the mental health education into English teaching. Questionnaire survey and analysis are conducted on the adaptability to the campus life of college students. With 
the understanding of their practical difficulties, this thesis is to give some advices on how to involve in the campus life as soon as possible.

College students with long-distance journey come to Jiujiang for further study. Facing the new environment, they may meet all kinds of difficulties about adapting to the campus life. Using a comprehensive method of documentations research, questionnaire survey and depth interview, this research takes the English major freshmen from Jiujiang University as research objects. This group is in a transition between high school and university undergraduate course phase. The learning knowledge links up with the high school education. The teaching environment and method are obviously different with high school but similar to university stage. Therefore, if students can adapt to the college campus life as soon as possible, it will help them learn English well in the future.

\section{Methodology}

The purpose of this paper is to analyze psychological factors in College English learning. The author, as a Chinese teacher teaching English in a university, is interested in mental phenomena while teaching students English. In order to get first-hand data and information to find out the answers, the author made a survey in Jiujiang University. And the author hoped this paper will be of some help to both language teachers and learners.

\subsection{Subjects}

All the subjects taken in this experiment are the freshmen English major college students from JiuJiang University. Their ages vary from 17 to 19, and they have similar English learning background. Most of them have been studying English for eight or more years. There are 3 classes (110 students) in total, including 8 males and 52 females. The author collects their English scores of college entrance examination. The highest score is 119 points. The lowest score is 35 points. The average score is 92.4 points. And there are 32 students who passed English examination.

\subsection{Instruments}

This thesis mainly uses the literature method, the questionnaire method and the interview method.

\subsubsection{Literature method}

All relevant literature and data information are collected and generalized, which are mainly from the National Library, Jiujiang University Library and Wanfang Data. Based on the analysis of the existing literature, the author determines the important part of the thesis and the main problems.

\subsubsection{Questionnaire method}

According to the existing data, compile the Jiujiang University Student Adaptability Situation Questionnaire, make Jiujiang University freshman students majored in business English as a sample, give out questionnaires and recycle, and then make statistical analysis on the status quo of college students' adaptability situation in Jiujiang University. 


\subsubsection{Interview method}

Aiming at specific problems, the individual freshmen and teachers in Jiujiang University are interviewed, and then the author will sum up the data.

\subsection{Research procedure}

First, 110 questionnaires are distributed, 100 questionnaires are back, and the rate is more than $90 \%$. Second, data will be sorted out jointly by the author's counting with the computer software, and mental factors and phenomena will be recognized and classified. Third, the author will analyze the possible reasons of those negative factors.

\section{Results and discussions}

The difficulties with high frequency that the English major freshmen encountered are the difficulty of learning, the financial problem, feel loneliness, the problem of getting on with others, poor English and so on. Among the above difficulties, the poor English is the biggest difficulty, and the loneliness feeling is the second one.

Table 1. Freshmen English Level

\begin{tabular}{llllll}
\hline & Excellent & Good & Common & Poor & Very poor \\
\hline Listening & $12.31 \%$ & $43.08 \%$ & $27.69 \%$ & $12.31 \%$ & $4.62 \%$ \\
Speaking & $4.62 \%$ & $32.31 \%$ & $38.46 \%$ & $20.00 \%$ & $4.62 \%$ \\
Reading & $4.62 \%$ & $35.38 \%$ & $43.08 \%$ & $12.31 \%$ & $4.62 \%$ \\
Writing & $6.15 \%$ & $15.38 \%$ & $47.69 \%$ & $20.00 \%$ & $10.77 \%$ \\
\hline
\end{tabular}

In this investigation, $55.38 \%$ of students think their listening ability is very good or relatively good, $27.69 \%$ of students think theirs are common, and $36.92 \%$ of students think theirs are poor or very poor. About the spoken English level, 36.92\% of students think theirs are excellent or good, $38.46 \%$ of students think theirs are just so-so and $24.62 \%$ of students think theirs are poor or very poor. About the reading English abilities, the number is respectively $40 \%, 43.08 \%$ and $16.92 \%$. About the writing level, the number is respectively $21.54 \%, 47.69 \%$ and $30.77 \%$.

\subsection{Common psychological problems in the process of college students' English learning}

This research shows that when people are in a state of certain kind of negative emotion, the cognitive activities will automatically stop. Even if it doesn't stop, there will be no practical effects. Because of the particularity of its teaching contents and methods, the college English teaching effects are especially vulnerable to the students' psychological factors, which is far greater than intelligence factor. A variety of psychological factors may cause many bad moods such as conflict, boredom, fear, escape and disdain in English learning. Due to the psychological and emotional flexibility and continuity, the individual student's negative psychological state is easy to affect other students, then to the whole teaching.

\subsubsection{Depression}


It mainly appears in the freshmen. There are two kinds of reason. First, it is the first time for many students to live alone far away from home, and they are all in the new environment, feeling lonely. Second, many students have unrealistic illusions about college life before entering universities. Even they think that teachers in the university are all senior scholarly professors. Actually, that is a fantasy.

\subsubsection{Inferiority complex}

Most students have low self-esteem. After untold hardships, many students have crossed the "single-plank bridge"-- the college entrance examination. Many students think that indeed there will be a peak pause for breath, and now reached the peak of despair only to discover that the mountain more than hypocritical, breathing moment forever ahead. Then their superiority suddenly disappeared, their attention transferred from advantages to disadvantages, which leads to low self-esteem.

\subsubsection{Learning-adaptability problems}

It is also a common psychological confusion for freshmen in university. The main reason is that they still prefer the teaching methods in middle school than in universities. Many middle school students are victims of indoctrination education. Middle school students just passively accept the teacher's instruction knowledge, but university teaching way is very different. More contents require students to master through self-study, and they should be independent and self-conscious. The English education of middle schools in China is almost a kind of exam-oriented education; teachers spend most of time in explaining the grammar and vocabulary, rarely on listening and speaking. However, according to the College English Teaching Program, college students are required to have very good reading comprehension ability and certain listening, speaking, writing and translation abilities, so that they can communicate in English.

\subsubsection{Slack off}

As a college teacher, I have seen many students with mental problem show no power, no pressure, no sense of urgency, lack of enthusiasm and indifference to their grades, and what's worse, avoid studying. This kind of situation happens mainly because those students' wrong fantasy about university life before entering universities and lack of life goals. Students think they can play at will after entering universities; they don't need to bury themselves in their books anymore, especially the English. Many students with poor English wrongly think English has nothing to do with their majors before admission, after getting into the university they can also escape from learning English "luckily". And they said they are disappointed in university, including the pressure of learning English.

\subsection{Some suggestions to solve the psychological problems}

Students have different psychological characteristics at different stages but these characteristics have something in common. In regard to how to face the troubles, different students take different measures and those measures are usually praying hard to god, spending time on hobbies, talking to other people as well as feeling sad without doing anything. Thus it can be found that untangling the psychological problems is difficult for most of students.. Only a few people would like to seek counseling and treatment, or ask for help from teach- 
ers who are in charge of classes. Therefore, teachers should understand students' situation and guide students at any time.

\subsubsection{How to teach the first lesson well}

A good beginning is half done. For the first class, teachers had better not go into the textbook directly, teachers should do the following:

(1) Attract students with fluent spoken English introduction, set up the teacher's authority and motivate students' interests in learning English.

(2) Tell students college English learning objectives, learning methods and the differences with high school, and clarify the learning tasks and requirements of college English.

(3) Expound the difficulties and problems in the process of adaptation they may meet, and give them your own suggestions. Make students prepare themselves for the changes from the beginning. Students should have a clear concept on what to learn and how to learn English in college.

\subsubsection{Good teachers should play model roles in the classroom}

The teachers' words, deeds, and movements in classroom, will affect students positively or negatively. It can make students china-southwest, exerts a subtle influence on teachers, and the aesthetic point of view, they also have direct guidance. Therefore, we cannot ignore the model role of teachers in the classroom. In order to improve the effects of English teaching, teachers should pay attention to those behaviors in the classroom about the following aspects:

\section{(1)Appearance}

The way a teacher dressed is a symbol of a kind of culture and image of teacher's thought. Therefore, it is a force which cannot be ignored. First, teachers in classroom must be welldressed, which seems to fit into the teacher's image; second, teachers' clothes should be clean and tidy. When teachers entered the classroom, the proper proportion of color, size of clothes may be chosen to be visually pleasing. Students can accept the teacher easily from the psychological respect, and be willing to listen to the teacher in class. On the contrary, students may dislike the teacher's weird clothes and hairstyles, not to mention to like those teachers' classes.

(2) Take a correct attitude towards teaching

In class, teacher's attitude is also very important. An attitude with open-hearted and deliberate characteristic should be applied to the class. Teachers should be with courteous manners, polite words, sublimated temper and profound intelligence. Sometimes, teachers may respond to relative emotions with the characters of joys and sorrows on books. In a word, teachers should be always consistent with the contents of the books. So that students would be closed with teachers from face-to-face talking, respect teachers. And it also boosts students' confidence and improves their self-esteem to learn English well.

(3) Blackboard writing

Writing on the blackboard will deepen students understanding of the contents by using visual image. Teachers should pay attention to the specific, methodical blackboard writing and give students visual aesthetic feeling.

(4) Sight

When having a lecture, teachers' sights should be oriented to the whole class, and pay attention to the students' mood in class. If problems are found, teachers should solve it in time. According to student's mood, teachers should change their teaching modes, adjust the 
classroom atmosphere, attract the attention of students, and improve the teaching effect. When lecturing, teachers should not look down at the floor, or look up at the ceiling, or look out of the window. These are undesirably negative psychological manifestations for students.

(5) Gestures

In classroom instruction, the gesture is an instructional way to impart knowledge. A good teacher who wants to have an active class should be good at using gestures, facial expressions, movements and so on to display and create scene. Only in this way can teachers make their class become and rich. And teachers should avoid some impolite actions. For example, picking nose and yawning. It is easy to mar teacher's image and students may also dislike it.

(6) Control emotions

The classroom teaching process is not only a process of mastering knowledge and influencing each other, but also a process of emotional communication and mutual affection between teachers and students. So teachers should not bring bad mood in life or work into the class. Teachers should present a good image to the students in class, which must be optimistic, positive and showing deep love towards life. A good teacher must be good at creating a relaxing and happy classroom atmosphere, which lets students be always in a positive, easy and good mental state. On the contrary, the teacher's bad mood and unhealthy behavior are likely to induce students' anxiety and even fear psychology, form a dull and depressing classroom atmosphere, thus cause students' unhealthy psychology. Therefore, teachers should pay more attention to their own images and become students' model in classroom. Furthermore, teachers should edify students by their own beautiful mind and noble moral sentiment.

\subsection{Dig deeply to see students' enthusiasm}

In connection with the learning problem, most students dislike to make study plans. Some students have incorrect attitude towards studying and they are usually lazy. Furthermore, quite a number of students cannot follow teachers or dislike the ways that teachers teach them, so they would never ask for help even if they meet difficulties. In addition, most students are anxious about their English learning. While there are still many students entered the universities with curiosity. In the process of adapting to college life, the selfconfident students tend to show high enthusiasm. At the same time, in order to establish their own image and obtain others' recognition, they have a strong desire to show themselves. These kinds of infectious enthusiasm and desire that people can't resist will drive those unconfident and less positive students automatically, and help them to create a favorable English learning atmosphere, which is a precious wealth for foreign language teachers and classes. But as time goes by, this kind of enthusiasm will become slowly cooling with students' decreasing curiosity, so the first semester grade is the key. If we use it and guide them at that time and try to make it continue, it will greatly benefit the future English teaching. Therefore, after entering universities, teachers should firstly observe the whole class, find out the positive students, and put them into different groups in order to drive the other team members, so that everyone has equal opportunity.

\subsection{Use the textbooks resources for mental health education}

College English textbook contents have been carefully selected by editors. We can find that the content of those textbooks are permeated with the author's thoughts, including the worldview, the outlook on life, and values in the articles. Therefore, in teaching, teachers 
should also combines the actual conditions of students' ideological situation for targeted education in addition to teaching language and culture knowledge. The post-90s freshmen are mostly on top of the material. These students have grown up under the family's care, their lack of learning initiative and self-consciousness largely depends on other people's supervision at any time. They generally study passively and they think learning is to meet their parents' expectations, while going to college is regarded as a task rather than the way of realizing self-pursuit. However, after entering college and being far away from home, they are easy to slack off on their learning without the constraints of family. What's worse, they no longer study hard and without planning and clear objectives in their campus life. In addition, non-English major students think English is no longer important in college, even some students think that they can learn English well only by rote, and English is useless. So being lack of motivation and confidence in English learning, some students are poor in English, which is one of the most important reasons in English learning. To these problems, when having the first English class to freshmen, teachers should clearly introduce that English courses are in important position in university curriculum and will affect the future professional development in order to correct the students' wrong ideas and the wrong attitudes to learn English. In addition, combined with the text theme, teachers should let students discuss the experiences and feelings of learning English, and summarize the characteristics and laws of foreign language learning.

Some strategies for learning English are the first unit theme in college English intensive reading course pressed by Shanghai foreign language education. In this paper, the author not only aims to introduce an effective English learning strategies and concrete methods, but also points out that learning English is never easy. Learning English requires constant effort and hard work, and both are used to test one's willpower. Teachers should organize students to discuss the theme and let them understand if they really want to learn foreign language well. First of all, they must have the determination, confidence and perseverance. Teachers should let them positively bear the responsibility of learning English and be the true master of study. Then let them grasp some English learning strategy effectively, which will greatly improve the efficiency of English learning. That is to say, the language learning also needs to pay attention to the strategy and tactics. The second unit theme is sailing round the world. This unit is about the great explorer Francis Chichester adventure story. In this adventure theme, let the students discuss the familiar adventurer in the world and their heroic deeds. It aims to make them understand that life is full of challenges, risks and crisis and they should have their own goals. In order to realize dreams, people should work hard and realize the value of life with persistent perseverance. Teachers can add some stories of great man that can play role models and guide students to establish correct outlook on life.

\section{Conclusions}

Based on the above study, advices are given as follows:

(1) Take psychological education to improve their psychological quality and adaptive capacity.

(2) Update the ideology of teaching management to improve their learning abilities.

(3) Strengthen the culture construction to build a culture-oriented campus atmosphere.

(4) Improve overall daily life of campus to benefit all the students.

This article simply analyzed some parts of the negative psychological factors in foreign language teaching. In fact, there are many positive and beneficial mental phenomena in foreign language teaching, such as the students' curiosity, aggressive, pleasure, their psychological satisfaction and so on. To guide and use these positive psychological phenomena reasonably is becoming an integral part of foreign language teaching. In the classroom 
teaching, through effective psychological quality education, teachers should consciously put the psychological education into classroom and gradually develop students' sound personality, so that they will not lose their heart even if they had some difficulties in the future life. If they not retreat and advance under pressure, this kind of spirit will benefit them through the life span. Also, they have a long life road. They might encounter all sorts of unexpected difficulties and setbacks. But as long as they have good psychological quality, they can enrich their life, not empty; they can have their courage to struggle and realize their value and they will not belittle themselves. College English teaching has its own features. Therefore, during the teaching, teachers should fully explore the moral factors in the English articles and be good at supplementing inspirational quotes simultaneously and enlightening students' thoughts. In addition, teachers should also train students' language comprehension abilities and make them deeply understand the true meaning of life, and then inspire them.

\section{References}

1. Arnold J. 1999. Affect in Language Learning. Cambridge: Cambridge University Press.

2. Rogers C. 1969. Freedom to Learn: A View of What Education Might Become Columbus. OH: Charles E. Merrill.

3. Zhihai He. 2003. Brief discussion of psychological education in class teaching. Journal of Shandong Education Institute, (1).

4. Zhongxu Li. 2001. Analysis of college students' learning psychological deviation. Theory Horizon, (3). 